\title{
An outbreak of tuberculosis affecting cattle and people on an Irish dairy farm, following the consumption of raw milk
}

Doran $\mathrm{P}^{1}$, Carson $\mathrm{J}^{2}$, Costello $\mathrm{E}^{3}$ and More $\mathrm{SJ}^{4}$

${ }^{1}$ District Veterinary Office, Enniscorthy, Co. Wexford, Ireland

${ }^{2}$ Wexford General Hospital, Wexford, Co. Wexford, Ireland

${ }^{3}$ Central Veterinary Research Laboratory, Backweston Campus, Celbridge, Co. Kildare, Ireland

${ }^{4}$ Centre for Veterinary Epidemiology and Risk Analysis, UCD School of Agriculture, Food Science and Veterinary Medicine, University College Dublin, Belfield, Dublin 4, Ireland

\section{ABSTRACT}

Bovine tuberculosis is an ongoing problem in Ireland, and herd incidence has remained at approximately $5 \%$ for some years. Spillover of infection from cattle to people remains an ever-present possibility, given the ongoing pool of infection in the Irish cattle population. This paper describes an outbreak of tuberculosis affecting cattle and people on a dairy farm in southeastern Ireland following the consumption of milk from a seven-year-old cow with tuberculous mastitis. Twenty-five of 28 calves born during autumn 2004 and spring 2005 were subsequently identified as TB reactors, and five of six family members were positive on the Mantoux test. During 2005 , milk from this cow had mainly been used to feed calves, and was added only occasionally to the bulk tank. Therefore, the calves each received infected milk on an almost continuous basis between birth and weaning. The family collected milk from the bulk milk tank, and consumed it without pasteurisation. This case highlights the risks associated with the consumption of raw milk. In this family, TB has had a very significant impact on the health of two young children. These risks are well recognised, and relevant information for farmers is available. It is of concern, therefore, that raw milk consumption remains prevalent on Irish farms. New strategies are needed, in partnership with industry, to address this important issue.

KEYWORDS: bovine tuberculosis, Ireland, mastitis, milk, Mycobacterium bovis, pasteurisation, TB, zoonosis

\section{CORRESPONDING AUTHOR:}

Paul Doran

District Veterinary Office

Enniscorthy, Co. Wexford, Ireland

E-mail: paul.doran@agriculture.gov.ie 
Bovine tuberculosis (TB; infection with Mycobacterium bovis) has been an ongoing problem in Ireland for many years. Prior to national control measures, disease in cattle was common. From 1929 to 1938, it was estimated that gross pathology consistent with tuberculosis was present in 31-33\% of cattle slaughtered at the city abattoirs in Dublin (Cotter et al. 1996). A national eradication programme commenced in 1954, in part as a consequence of public health concerns, leading to a substantial reduction in disease prevalence by the mid 1960s (More and Good 2006). Although subsequent progress has slowed, herd incidence has remained at approximately $5 \%$ for some years. The eradication programme is complex (More and Good 2006), but includes annual testing of all Irish cattle with the single intradermal comparative cervical tuberculin (SICCT) test.

There have been substantial changes in the epidemiology of human tuberculosis in Europe, including Ireland.

Throughout the $19^{\text {th }}$ and early $20^{\text {th }}$ century, a substantial proportion of human tuberculosis cases were caused by infection with M. bovis (Thoen et al. 2007), generally linked to the consumption of raw cows' milk (de la Rua-Domenech 2006; Quinn et al. 2006). In recent years, however, human infection with $M$. bovis has become very uncommon, accounting for between $1 \%$ and $4 \%$ of culture-confirmed tuberculosis cases (that is, cases attributed to infection with organisms of the Mycobacterium tuberculosis complex, of which M. bovis is a member) in Ireland between 2000 and 2004 (Jackson et al. 2007; Anon. 2008).

Spillover of infection from cattle to people remains an ever-present possibility, given the ongoing pool of infection in the Irish cattle population. This paper describes an outbreak of tuberculosis affecting cattle and people on a dairy farm in 2005 , following the consumption of raw milk from a cow with tuberculous mastitis.

\section{CASE HISTORY \\ The farm}

The 41 ha. farm ('the case farm') was located in the south east of Ireland. It was divided into four non-contiguous fragments, including three (Fragments 1, 2 and 4), which were grazed by cattle each spring and summer (Figure 1). A final fragment (Fragment 3), of 3.5 ha., was used exclusively for tillage. The farm was managed solely by the herd owner. Although the farm was an operating dairy, the farmer also fattened home-bred steers for sale. In March 2005, there were 100 cattle on the farm, including 38 cows, 32 steers, eight heifers and 22 calves. The farmer had no other commercial livestock, such as goats or deer, and no cats. A dog had been present on the farm, however in February 2005, this animal was treated for suspected paraquat poisoning and subsequently died after a road traffic accident.

Farm management was consistent from year to year (Figure 2). The milking cows remained on the home farm (Fragment 1) throughout the year, including a period of housing each winter (from November to March: adult winter housing). The cows calved in either spring or autumn, and the calves were held with their dam for approximately one week following birth. Autumn-born and early spring-born calves were housed (in designated calf housing in batches of three to four similar-aged calves, well-separated from other

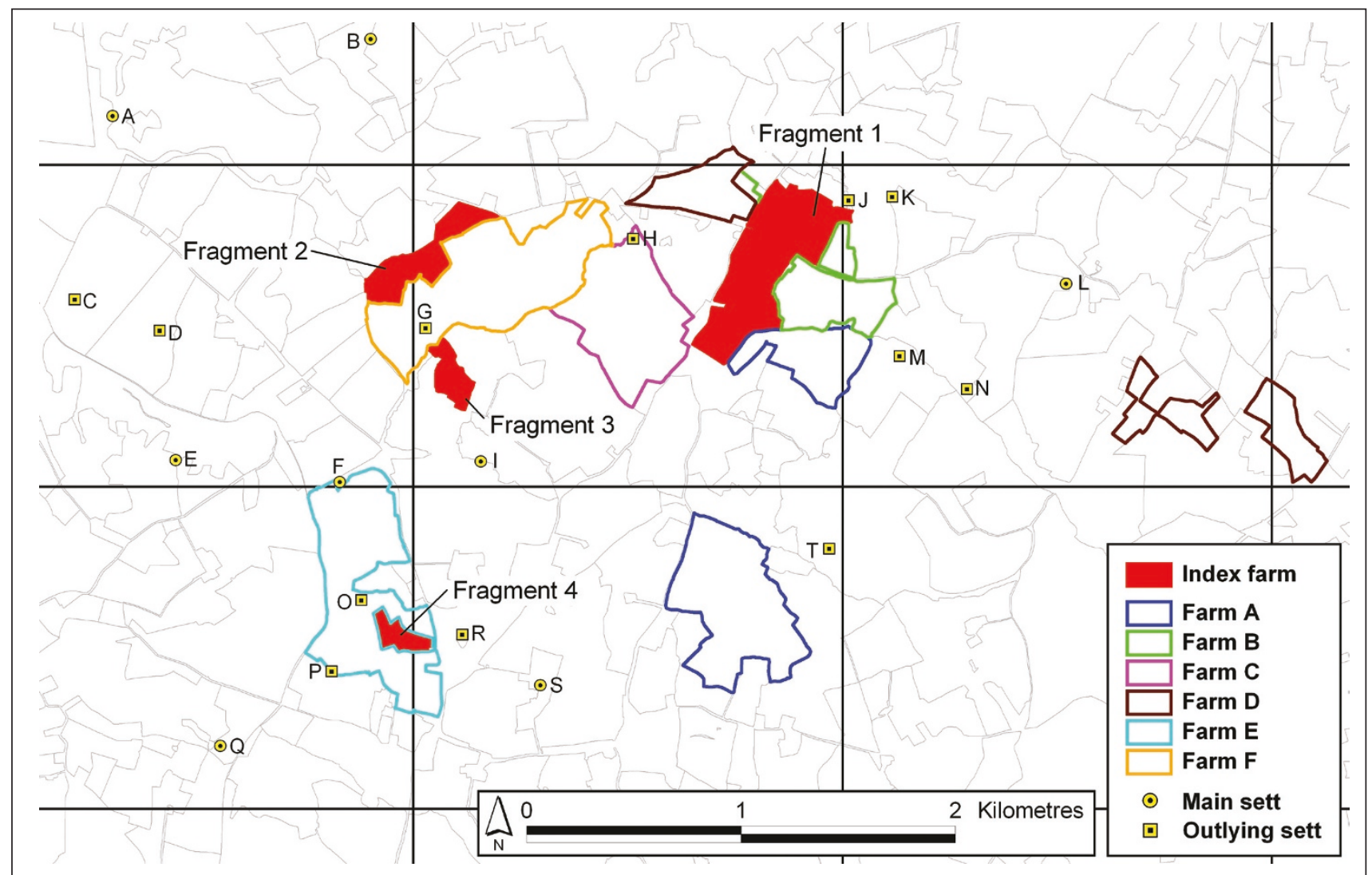

Figure 1: The farm fragements which were grazed by cattle at 'the case farm'. 
animals) from soon-following-birth until late April/early May, then turned out to pasture on Fragment 1 (May to September, designated pasture separate from the milking cows) and Fragment 4 (October to November, post-silage production). Late spring-born calves were added to this group during late spring and summer. During housing and prior to weaning, calves were fed hay, and approximately $1 \mathrm{~kg}$ of calf concentrate ration and five litres of 'discard' milk per day (from cows immediately post-calving, those with mastitis or high somatic cell count, and those with milk withheld due to medicine withhold requirements). Yearling animals were also held in adult cattle housing on Fragment 1, but grazed pasture on Fragment 2 during spring and summer. Older (two-year-old) steers were housed for fattening. During winter housing, adult cattle were fed silage and rolled barley (each home-grown) and housed in a line of pens (in order: two-year-old steers, yearlings, dry cows, milking cows) under a common roof. There was ready contact between animals in adjacent pens, but not otherwise.

The farm was maintained as a closed unit. There had been no cattle introductions for six years prior to 2005 , and all cows were artificially inseminated. The farm was well fenced and there was no history of contact with any animals from other herds. Animals were moved between Fragments 1 and 2, and between Fragments 1 and 4, on foot and via farm vehicle, respectively. Water was sourced from either a deep sealed well (the southern part of Fragment 1) or a mains supply (all other areas), and supplied to water troughs (some less than 28 inches high, not all free-standing). No machinery, housing, crushes or other facilities were shared with other farms, and all slurry and manure spreading was conducted by the herd owner. Liquid milk was stored in a bulk tank, before collection for processing by a local milk cooperative. Raw (unpasteurised) milk from the bulk tank was used routinely by the farm family. A total of six people lived on the farm, including the farmer and his wife, a grandparent, and three children (aged four, seven and 14).

\section{Tuberculosis in animals}

The tuberculosis testing history on the case farm is presented in Figure 3. Between 1989 and 2004, the farm had been restricted during 1993 (with one reactor), 1995

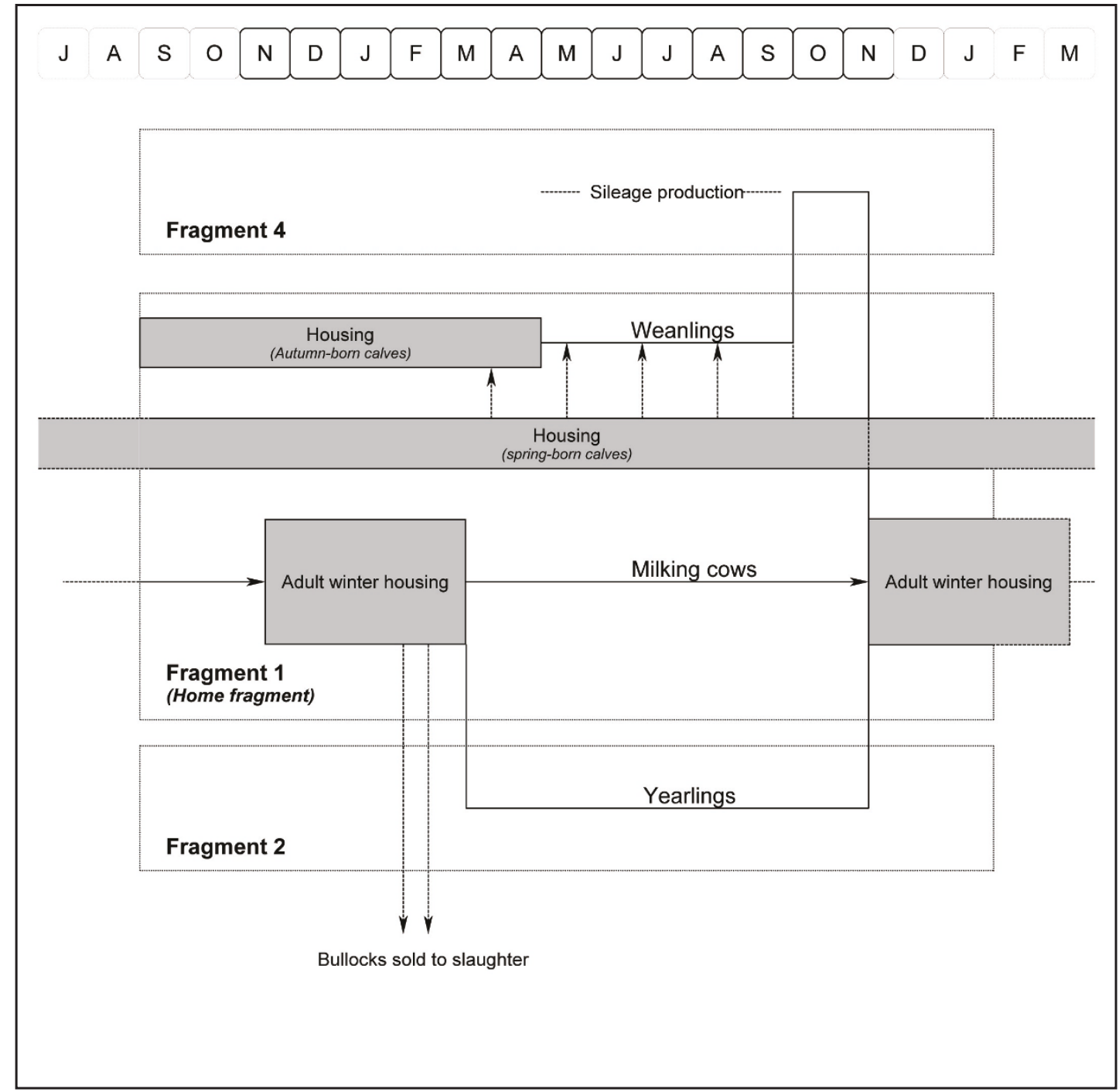

(5), 2003 (1) and 2004 (1): in the latter three years with confirmed infection (that is, with TB-lesions in at least one reactor at post mortem). The herd experienced a significant TB breakdown, following initial detection on March 12, 2005, with 38 tuberculin reactors including seven cows, two-yearold animals (three steers), one-year-old animals (two steers, one heifer) and calves (13 autumn-born, 12 spring-born). At the tests in March and June 2005, 
were detected on routine gross post mortem examination in $13(48 \%)$ of these reactors, including two (67\%) twoyear-old animals and eight (80\%) autumn-born calves and three $(75 \%)$ spring-born calves. The 11 reactors detected in September 2005 were removed alive as part of an unrelated tuberculin assay trial. They were subsequently slaughtered in July 2006. At post mortem, TB-like lesions were detected in eight of these animals.

Tuberculous mastitis was diagnosed in a seven-yearold cow (no. 044) on July 7 , 2005 , following the isolation of $M$. bovis from a milk sample obtained from a mastitic quarter, after culture on Bactec 460 liquid culture system

(Becton Dickinson Biosciences, Sparks, MD, USA) and isolate identification by AccuProbe (Gen-Probe Inc., San Diego, CA, USA) and GenoType MTBC (Hain Diagnostika, Nehren, Germany). M. bovis was not isolated from the three unaffected quarters. The 2005 lactation commenced, at calving, on January 12 , 2005. Previously, the 2003/04 lactation extended from August 18, 2003 (calving) to November 15, 2004 (drying-off). As a result of chronic mastitis in one quarter (and an associated high somatic cell count; Figure 4), this cow's milk was mainly withheld from the bulk tank and fed to calves without treatment (that is, it was neither boiled nor pasteurised). The quarter was hard on palpation, with the consistency of the milk changing over time between thick and watery. However, on an intermittent basis (cumulatively for approximately three weeks) during the 2005 lactation, milk from cow no. 044 was added to the bulk tank. This cow had been negative to the SICCT on each of seven occasions since 2003, but was positive to an antibody-based anamnestic ELISA (Costello et al. 1997) using bovine purified protein derivative (PPD) antigen on July 7, 2005. The ELISA was done because it is a suitable test for the detection of anergic animals and there was a suspicion that cow no. 044 was such an animal. The test is used infrequently

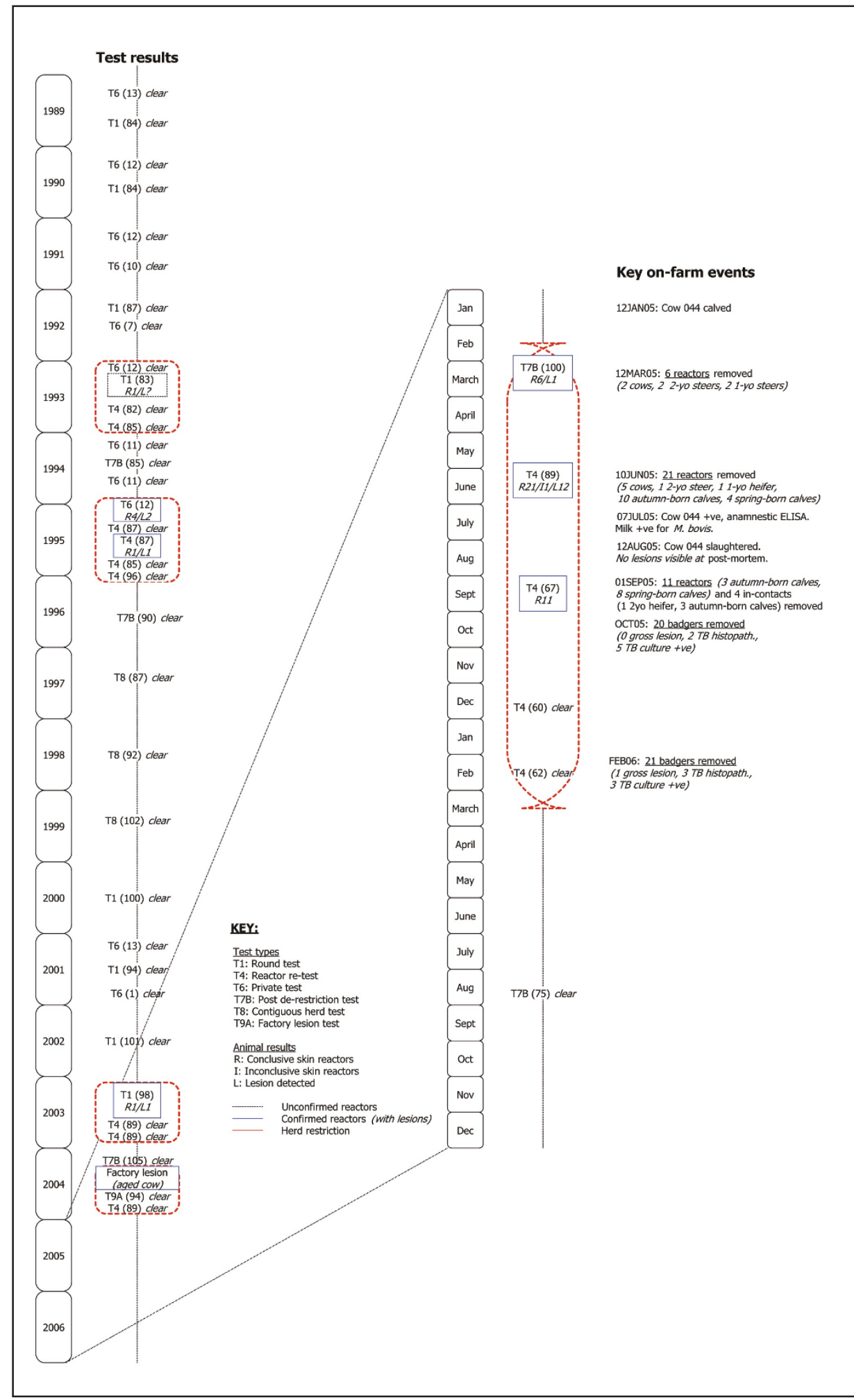

Figure 3: The testing history for tuberculosis on the case farm during 1989 to 2006. The test types include the round test (T1), the inconclusive re-test (T3), the reactor re-test (T4), the high incidence area test (T5C), the private test (T6), the post de-restriction test (T7B), the contiguous herd test (T8) and the factory lesion test (T9A). In this figure, the number of conclusive skin reactors (R), inconclusive skin reactors (I) and lesions detected (L) at each test are also presented. The herd was unable to trade, due to tuberculosis, during the periods encompassed by the red dashed line. The presence of unconfirmed and confirmed reactors is indicated by the dashed black and solid blue box, respectively. 
in the management of Irish reactor herds, usually when anergic cases are suspected. This cow was slaughtered on August 12, 2005. No detailed post mortem was conducted. No lesions were detected in lymph nodes, including the supramammary lymph nodes, during routine abattoir inspection. The mammary gland was not examined. $M$. bovis was subsequently cultured from a supramammary lymph node.

The locality surrounding the case farm was not considered problematic for tuberculosis. A total of six cattle farms (Farms A-F) had land directly contiguous to Fragments 1, 2 and/or 4 of the case farm (Figure 1). Since 1998, there had been two TB breakdowns on Farm $\mathrm{F}$ (one confirmed reactor in 1998/99; one unconfirmed reactor in 2003/04), one on Farm B (three unconfirmed reactors in 2001/02) and none on the remainder.

Badgers were captured in this locality within a radius of approximately two kilometers of Fragments 1, 2 and 4 on two occasions, in October 2005 and February 2006. A total of 41 badgers were removed from an area of 16.77 sq. kilometres (20 in 2005, 21 in 2006), and all were subjected to post mortem examination. One of these animals had gross lesions consistent with TB. Of 22 badgers examined histopathologically, five (including two captured in 2005 and three in 2006) were positive. Of 18 badgers examined microbiologically, eight (including five in 2005 and three in 2006) were positive. In total, based on results from histopathology and/or microbiology, 11 of 32 (34.4\%; including 35.0\% in 2005 and 33.3\% in 2006) badgers had evidence of $M$. bovis infection.

\section{Tuberculosis in people}

Six family members (grandmother, father, mother, 14-yearold girl, two boys aged seven and four) lived on the farm.

The father, mother and 14-year-old girl had previously been vaccinated using BCG.

In June 2005, Mantoux testing was conducted on all family members, using two tuberculin units injected intradermally. The results of this test were as follows: grandmother (no induration), father (14 $\mathrm{mm}$ diameter induration), mother (12 $\mathrm{mm}), 14$-year-old ( $8 \mathrm{~mm})$, seven-year-old $(12 \mathrm{~mm}$ ) and fouryear-old $(14 \mathrm{~mm})$. Chest $\mathrm{x}$-rays on all individuals showed no abnormalities.

The seven-year-old boy had no evidence of clinical TB and was treated as latent TB with prophylactic isoniazid initially, then rifampicin for a total of six months.

The four-year-old boy had two enlarged (approximately 5 $\mathrm{mm}$ diameter) lymph nodes in the right anterior triangle of the neck. Biopsy revealed acid-fast bacteria in these lymph nodes, but TB culture was negative. Pathological examination of the lymph nodes on microscopy showed partially opened cystic lesions measuring $1.5 \mathrm{~cm}$ in maximum diameter, which contained creamy friable material. There were further features of caseating granulomas and some lymphoid tissue on microscopy, which were highly suspicious of tuberculosis. This child was considered an active case of TB. The initial drug choice (ethambutol, pyrazinamide, rifampicin and isoniazid) was modified to ethambutol and rifampicin, once antibiotic sensitivity results (highlighting partial resistance to isoniazid and pyrazinamide) became available from the culture of milk from cow no. 044. Treatment continued for 13 months. There were no liver or ocular complications from the treatment. Four months after this boy had stopped treatment, a swelling recurred in the same site on the right side of his neck. On excision biopsy, caseating necrosis was seen in a lymph node with surrounding lymphohistiocytic granulomatous reaction. There was no evidence of acid-fast bacteria and TB culture was negative. Full immunological assessment was normal. A differential diagnosis of re-infection, relapse of either M. bovis, M. tuberculosis, atypical mycobacteria or delayed immune reconstitution syndrome was made. Atypical mycobacteria were essentially excluded by a positive blood quantiferon test (Mahomed et al. 2006), which would confirm the diagnosis of TB but would not discriminate between $M$. bovis or M. tuberculosis. Treatment was restarted with azithromycin, 
ethambutol, isoniazid, rifampicin and pyrazinamide and was continued for six months (with the exception of azithromycin and pyrazinamide, which were discontinued after two months). The swelling subsided and no further treatment is planned at the time of writing this article.

The grandmother, parents and 14-year-old child had no overt signs of disease, and no treatment was undertaken.

\section{VNTR profiling}

VNTR typing was conducted on $M$. bovis isolated from the milk sample from cow no. 044 in July, 2005 and from five badgers captured in October, 2005, based on six VNTR Ioci: QUB11a, QUB11b, ETRA, MIRU26, VNTR4052 and VNTR1895 and using primers and PCR conditions as described by Roring et al. (2004). Although M. bovis was isolated from the supramammary lymph node from cow no. 044 in August 2005 and a further three badgers in February 2006, VNTR typing is not available. Mycobacterial organisms were not cultured from the human cases.

Three different VNTR profiles were identified (i: 11465 44 based on the earlier loci sequence, ii: 1147634 , iii: 103754 4). The isolates from the milk and from two badgers (captured at setts J and S, [Figure 1] ) were each VNTR profile i. Different VNTR profiles (ii and iii) were found in two badgers captured at sett N. VNTR profile iii was also identified in a badger captured at sett $\mathrm{H}$.

\section{DISCUSSION}

This paper reports an outbreak of bovine TB in cattle and people following the consumption of raw milk on an Irish dairy farm, which clearly demonstrates the infection risk for calves and people associated with a case of tuberculous mastitis. A wide range of measures are in place to minimise transmission between animals and people (More and Good 2006), and infection is now very rare. However, these measures do not address practices such as on farm pasteurisation, which remain the responsibility of individual farmers. The case highlights the importance of this on farm measure.

During 2005, a substantial number of calves and people became infected following the consumption of milk from cow no. 044 (there is no evidence suggesting additional cases of tuberculous mastitis on the case farm). Of 16 and 12 calves born during autumn 2004 and spring 2005, 13 (81.3\%) and 12 (100\%), respectively, were subsequently identified as TB reactors between June and September 2005. Similarly, five of six family members were positive on the Mantoux test in June 2005. Although it is likely that some of these people were infected with $M$. bovis, bacteriology was negative, both on biopsy and sputum samples. The 2005 spring- and autumn-born calves each received infected milk on an almost continuous basis between birth and weaning. Due to milk quota restrictions, extended feeding of whole milk was undertaken in this herd. Generally, two cows (including cow no. 044) contributed to the discard milk, and calves were weaned at various ages between five and eight months. On June 10,2005 , lesions were detected in three spring-born calves (at most, four-months-of-age), which highlights the degree to which this milk was infectious. These findings are consistent with earlier work by Rentería Evangelista and Hemández De Anda (1996), who examined the role of colostrum and milk management in modifying $M$. bovis exposure risk in calves in TB-infected herds. They are also supported by information from the human cases. The family collected milk from the bulk milk tank, and consumed it without pasteurisation. During 2005, they will have had only very limited exposure to the milk from cow no. 044, because it was rarely added to the bulk tank, and will have been substantially diluted in any case. It is not possible to determine when cow no. 044 first became infected, although it should be noted that this cow had been consistently negative when tested using the SICCT on seven occasions since 2003. Although a substantial increase in the somatic cell count was observed during the latter third of the 2003/04 lactation (Figure 4), there is no indication that this cow was infectious until her 2005 lactation.

The consumption of raw milk does not fully explain the transmission of infection among cattle within the case herd. In addition to the 25 milk-fed calves, there were a further 13 SICCT reactors among the older animals, including milking cows (seven animals), steers (three twoyear-old animals, two one-year-old animals) and a heifer (one-year-old). Cow no. 044 may have been the index case during this outbreak. Pulmonary lesions were not detected, however, only a very limited examination is possible at abattoir post mortem inspection. The immunological profile of high antibody levels and an absence of skin reactivity to tuberculin has been associated with progressive disease and possible respiratory shedding of $M$. bovis (Welsh et al. 2005). This animal remained with each of the other milking cows (including six animals that subsequently reacted to the SICCT) throughout the year, but did not have direct contact with the younger stock, either whilst grazing or in housing. It is very unlikely that the younger animals had been infected during a previous lactation (for example, in 2004) since other cases would have been expected; further, extensive testing had been conducted during this period. Other alternatives are also feasible (for example, a number of animals infected independently from a common source). Although the initial transmission components remain uncertain, cow no. 044 played a key role in the later transmission of infection to the calves and the family. No other cows in the herd were screened for $M$. bovis in milk, nor were subjected to the anamnestic ELISA. No further cases occurred in calves in the herd after the animals that had been fed untreated milk from cow no. 044 were removed.

The TB outbreak during 2003 to 2005 in the case herd was the result of either residual infection or introduction from wildlife, although the latter seems more likely. The case farm had last experienced a confirmed TB outbreak in 1995, and it is possible that one or more animals, including the aged cow with lesions detected at slaughter in 2004, may have been infected (but remained anergic) 
during the intervening period. Note that cow no. 044 was born in 1998, three years after this earlier outbreak. Similarly, a diverse range of $M$. bovis strains, suggesting complex infection dynamics, are prevalent in local wildlife. Three different $M$. bovis strains were found in the locality, including strains with two different VNTR profiles in badgers from the same sett. The $M$. bovis isolate was identical from cow no. 044 and from badgers from two setts, including one adjacent to Fragment 1 (the home farm). This information provides no indication of the direction of transmission (badgers to cattle, cattle to badgers), nor can it distinguish whether both species were exposed to an independent common source. Nonetheless, earlier work has highlighted the importance of badgers in the epidemiology of bovine tuberculosis in Ireland (Griffin et al. 2005). There is no evidence to support introduction of infection through purchased infection and as a result of spread from neighbouring farms. No cattle had been introduced onto the case farm for six years prior to 2005. Furthermore, there was a high level of biosecurity on the case farm, and no opportunity for direct contact with cattle on neighbouring farms. The area was not a TB 'hot-spot'. This herd experienced a further TB breakdown in 2007, following a positive herd test on August 16, 2007. At this test, four SICCT reactors were identified, including one cow with miliary TB. It is currently unclear if the 2007 breakdown is due to residual recrudescence or further wildlife involvement.

Bovine infection with $M$. bovis has been eliminated or substantially reduced throughout Europe, and, as a consequence, is generally not considered a substantial zoonotic risk. Nonetheless, potential exposure to infected milk remains a hazard for the population, and particularly for some occupational groups. Public health concerns have recently been raised in the UK following the resurgence of $M$. bovis infection in cattle (de la Rua-Domenech 2006; Evans et al. 2007; Jalava et al. 2007), and it is recognised as an ongoing zoonotic risk in other industrialised countries, including Canada (Fanning et al. 1991; Liss et al. 1994) and New Zealand (Baker et al. 2006).

Although $M$. bovis remains prevalent in the Irish cattle population (More and Good 2006), many measures are in place to limit exposure to the human population. In particular, the majority of infected cattle are removed early in their clinical course as a consequence of annual tuberculin skin testing. Furthermore, an administrative ban on the sale of raw milk was introduced in Ireland in 1997 and remained in place until the EU hygiene package was introduced in 2006. Under this package, the sale of raw cow's milk for direct human consumption in Ireland is now affected by herd TB-status. Regulation (EC) No 853/2004 of the European Parliament and of the Council (including subsequent corrigendum and amendments; Anon. 2004) prohibits milk of reactor animals (including inconclusive reactors and animals showing signs of tuberculosis) from entering the food chain from the time tuberculosis has been diagnosed (Anon. 2008). This milk can only be fed to calves if adequately heat-treated. Milk from non-reactor animals in these same herds can be used for human consumption and for the manufacture of dairy products on condition that it is first heat treated by an establishment authorised by the Department of Agriculture, Fisheries and Food. Nonetheless, herd-owners are strongly advised not to use or drink unpasteurised milk in the home, while there is disease in the herd. The widespread practice of feeding untreated surplus/discard cow's milk also presents a hazard, both for the animals and for the handlers. However, there is no legal requirement for heat-treatment of such milk, even if taken from mastitic cows, unless they are infected, or suspected of being infected, with TB. In summary, this legislation prohibits the use of raw milk from herds that are not officially TB free for the manufacture of milk or dairy products such as cheese. As an additional risk communication device, Regulation (EC) No 853/2004 also requires unpasteurised dairy products to be labelled 'made with raw milk' to enable consumers to make informed choices (Anon. 2008). Therefore, producers may sell unpasteurised dairy products, (such as cheese, cream, ice-cream or yoghurt), directly from officially TB free farms, but only if registered and approved to do so by the Department of Agriculture, Fisheries and Food. The abovementioned EU regulations also provide for Member States to introduce national rules for prohibiting or restricting the sale of raw cow's milk for direct human consumption from officially TB free herds, and the Irish government has stated its intention to shortly introduce a ban on the sale of such milk.

This case highlights the risks associated with the consumption of raw milk. In this family, TB has had a very significant impact on the health of two young children. These risks are well recognised (Buckley et al. 1998; Anon. 2008), and relevant information for farmers is available (Anon. 2005). It is of concern, therefore, that raw milk consumption remains prevalent on Irish farms. In a survey of 230 liquid milk suppliers in eight Irish counties, families on $84 \%$ of farms reported the consumption of unpasteurised milk (Buckley et al. 1998). There seems little doubt that new strategies are needed, in partnership with industry, to address this important issue.

\section{ACKNOWLEDGEMENTS}

We gratefully acknowledge the help of the family throughout this investigation. We also thank Joanne McLernon and Daniel Collins, who completed the VNTR typing and mapping, respectively. We acknowledge assistance from personnel at the Kilkenny Regional Veterinary Laboratory and the Irish Equine Centre.

\section{REFERENCES}

Anon. (2004) Regulation (EC) No 853/2004 of the European Parliament and of the Council of 29 April 2004 laying down specific hygiene rules for food of animal origin. Official Journal of the European Communities L226, 22-82. 25 June 2004 (including successive amendments and corrigenda).

Anon. (2005) Pasteurisation: health risks from 
unpasteurised milk. [Internet] In Farm Industry Leaflets, Food Safety Authority of Ireland, Dublin. Available from: www.fsai.ie/resources_publications. html. [Accessed 01 May 2009].

Anon. (2008) Zoonotic tuberculosis and food safety. (2nd edn) [Internet] Food Safety Authority of Ireland, Dublin. Available from: http://www.fsai.ie/resources_ publications.html [Accessed 01 May 2009].

Baker MG, Lopez LD, Cannon MC et al. (2006) Continuing Mycobacterium bovis transmission from animals to humans in New Zealand. Epidemiology \& Infection 134, 1068-1073.

Buckley J, McRory F and Mahony P (1998) On farm study of consumption of unpasteurised milk. Food Safety Authority of Ireland, Dublin. [Internet] Available from: www.fsai.ie/resources_publications.html. [Accessed 01 May 2009].

Costello E, O'Reilly PF, Yearsley DK et al. (1997) A study of an enzyme-linked immunosorbent assay for the diagnosis of tuberculosis in cattle. Irish Veterinary Journal 50, 35-38.

Cotter TP, Sheehan S, Cryan B et al. (1996). Tuberculosis due to Mycobacterium bovis in humans in the southwest region of Ireland: is there a relationship with infection prevalence in cattle? Tubercle and Lung Disease 77, 545-548.

de la Rua-Domenech R (2006) Human Mycobacterium bovis infection in the United Kingdom: incidence, risks, control measures and review of the zoonotic aspects of bovine tuberculosis. Tuberculosis 86, 77-109.

Evans JA, Smith EG, Banerjee A et al. (2007) Cluster of human tuberculosis caused by Mycobacterium bovis: evidence for person-to-person transmission. The Lancet 369, 1270-1276.

Fanning A, Edwards S (1991) Mycobacterium bovis infection in human beings in contact with elk (Cervus elaphus) in Alberta, Canada. The Lancet 338, 1253-1255.

Griffin JM, Williams DH, Kelly GE et al. (2005) The impact of badger removal on the control of tuberculosis in cattle herds in Ireland. Preventive Veterinary Medicine 67, 237-266.

Jackson S, O’Donnell K, O’Donnell J et al. (2007) Report on the epidemiology of tuberculosis in Ireland 2005. [Internet] Health Protection Surveillance Centre, Dublin. Available from: www.ndsc.ie/hpsc/AZ/ VaccinePreventable/TuberculosisTB/Publications/ AnnualReportsontheEpidemiologyofTBinlreland/ [Accessed 01 May 2009].

Jalava K, Jones JA, Goodchild T et al. (2007) No increase in human cases of Mycobacterium bovis disease despite resurgence of infections in cattle in the United Kingdom. Epidemiology \& Infection 135, 40-45.

Liss GM, Wong L, Kittle DC et al. (1994) Occupational exposure to Mycobacterium bovis infection in deer and elk in Ontario. Canadian Journal of Public Health 85, 326-329.

Mahomed H, Hughes EJ, Hawkridge T et al. (2006) Comparison of Mantoux skin test with three generations of a whole blood IFN- $\gamma$ assay for tuberculosis infection. International Journal of Tuberculosis and Lung Disease 10, 310-316.

More SJ, Good M (2006) The tuberculosis eradication programme in Ireland: A review of scientific and policy advances since 1988. Veterinary Microbiology 112, 239-251.

Quinn PJ, Collins JD (2006) The effect of wildlife reservoirs of Mycobacterium bovis on programs for the eradication of tuberculosis in cattle in Ireland. In: Thoen CO, Steele $\mathrm{JH}$, Gilsdorf MJ (eds), Mycobacterium bovis infection in animals and humans. Blackwell Publishing, Ames, lowa. Pp 124-135.

Rentería Evangelista TB, Hemández De Anda J (1996) Tuberculosis in dairy calves: risk of Mycobacterium spp. exposure associated with management of colostrum and milk. Preventive Veterinary Medicine 27, 23-27.

Thoen CO, Lobue PA (2007) Mycobacterium bovis tuberculosis: forgotten, but not gone. The Lancet 369, 1236-1238.

Welsh MD, Cunningham RT, Corbett DM et al. (2005) Influence of pathological progression on the balance between cellular and humoral immune responses in bovine tuberculosis. Immunology 114, 101-111. 